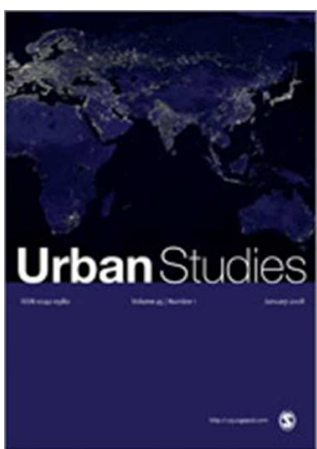

\title{
Mixed neighbourhoods and native out-mobility in the Oslo region: the importance of parenthood
}

\begin{tabular}{|c|c|}
\hline Journal: & Urban Studies \\
\hline Manuscript ID & CUS-1127-17-12 \\
\hline Manuscript Type: & Article \\
\hline $\begin{array}{l}<b>\text { Discipline: Please select a } \\
\text { keyword from the following list } \\
\text { that best describes the } \\
\text { discipline used in your paper.: }\end{array}$ & Geography \\
\hline $\begin{array}{r}\text { World Region: Please select } \\
\text { the region(s) that best reflect } \\
\text { the focus of your paper. } \\
\text { Names of individual countries, } \\
\text { cities \& economic groupings } \\
\text { should appear in the title } \\
\text { where appropriate.: }\end{array}$ & Western Europe \\
\hline $\begin{array}{l}\text { Major Topic: Please identify up } \\
\text { to } 5 \text { topics that best identify } \\
\text { the subject of your article.: }\end{array}$ & $\begin{array}{l}\text { Neighbourhood, Housing, Diversity/Cohesion/Segregation, Race/Ethnicity, } \\
\text { Demographics }\end{array}$ \\
\hline $\begin{array}{l}\text { You may add up to } 2 \text { further } \\
\text { relevant keywords of your } \\
\text { choosing below: }\end{array}$ & residential mobility, parenthood \\
\hline
\end{tabular}




\title{
Mixed neighbourhoods and native out-mobility in the Oslo region: the importance of parenthood
}

\begin{abstract}
The extent to which the native-born population accept living in multi-ethnic neighbourhoods is receiving more and more attention throughout Europe. The Norwegian debate around this topic started in the 1990s and tends to centre on education and children's welfare. Thus, our main question is whether native parents are prone to leave neighbourhoods with a high share of ethnic minorities. For this purpose, we utilize 'white flight' theory, particularly Ingrid Gould Ellen's revised proxy thesis. The key mechanism, according to Ellen, is fear of neighbourhood decline. Drawing on register data for the Oslo area, and tracking moves in 2010, we provide circumstantial evidence for the thesis. Both parents and parents-to-be are more sensitive to the concentration of ethnic minorities than are households without children. The size of the effect depends upon housing tenure, with a higher level of out-mobility among homeowners. There is also a marked geographic pattern, with less stability in Oslo East. None of these patterns was found in a control group consisting of non-natives. We conclude by highlighting the importance of housing structure and housing diversity policies.
\end{abstract}

\section{Keywords}

Land use, Planning, Policy, Transport, Economic processes, Urban modelling, Greenspace

\section{Introduction}

The term 'white flight' ('hvit flukt') was introduced to the general public in Norway in December 2006. A film director, Christopher Owe, used the term as a catchall phrase for perceived large-scale mobility out of Holmlia, a satellite town on the outskirts of Oslo. Critics immediately lashed out at the film for its form and content, but these reactions did not stop the proliferation of the flight metaphor. It spread within a few years to major newspapers, academic journals and electronic media. ${ }^{1}$

Similar concerns about population turnover are evident elsewhere in Europe, e.g. in Sweden (Aldén et al., 2015) and the United Kingdom (Johnston et al., 2015). However, while ethnicity may affect the level of mobility, several other factors are equally interesting. Ethnic minorities often live in neighbourhoods that also contain social problems, pollution, low housing quality and lack of amenities. It is not surprising that such neighbourhoods are marked by instability and demographic change. Both ecological theory (Hoyt, 1939) and 
recent studies of migration flows (South and Crowder, 1997; Andersson and Bråmå, 2004; Bailey and Livingston, 2008) suggest that families and individuals attempt to escape distressed neighbourhoods. Such outflows depend on many factors, one of which is a shared fear of neighbourhood change. If a large section of the public, particularly the native population, expect a rapid population turnover, they may also decide to leave the neighbourhood (Taub et al., 1984; Ellen, 2000a).

The idea that tolerant people want to escape mixed neighbourhoods has a particular appeal in the Norwegian context. A prominent politician stated as early as 1992 that he and his family considered changing neighbourhoods because of the high proportion of minority pupils in the local school. The same motive has later become a flash point in the integrationsegregation debate, in both local and national media. A search in a database (Atekst) reveals this bias very clearly: around $70 \%$ of all articles in newspapers, journals and electronic media which referred to 'white flight' over the period 2006 to 2015 brought up education or childwelfare as a mobility motive. ${ }^{2}$

The question we ask in this paper, therefore, is whether native parents in the Oslo area are prone to move out of mixed neighbourhoods. Three more detailed questions concern the context of departure: 1) Is the level of out-mobility different for parents who own their homes and those who rent? 2) Is the share of minorities the key factor behind native departure, or is change in the share more important? 3) How do native parents respond to specific levels of ethnic minority concentration (e.g. 10\%, 20\%, 30\%, etc.)? We further examine how individual movements are distributed in space: 4) Which parts of Oslo are mostly affected by large-scale turnover among native parents?

We conduct two types of control. First, we control for deprivation, change in deprivation and housing structure at the neighbourhood level, and age, gender, civil status, education, income, reception of benefits and location at the individual level. Second, we perform identical analyses for a control group consisting of non-natives.

Our work is to a large extent influenced by American research on white flight. Despite this influence, we do not endorse a sweeping use of the flight metaphor. 'White flight' is closely associated with intergroup relations between Anglo and African-Americans, particularly in terms of the growth of inner city ghettos (Massey and Denton, 1993). 'Native flight' is less conditioned by a specific historiography, but it does suggest a massive population turnover which is typical for US cities. We therefore adopt a broader concept, 'native out-mobility'. 
Another central term is 'mixed neighbourhoods'. For our purpose, we do not require a large degree of ethnic diversity (i.e. plurality of ethnic groups). 'Mixed neighbourhoods' are clusters of residences which, among several spatial attributes, have a large proportion of ethnic minorities. 'Ethnic concentration' is an umbrella term that places all neighbourhoods on a continuum from low to high.

\section{Theoretical background}

The notion that Whites retreat from areas that begin to attract Black residents, i.e. the white flight hypothesis, exists in three variants. The first one dates back to the $1920 \mathrm{~s}$, and emphasizes race as a singular factor behind white departure. Early work often relied on simple evidence regarding racial turnover at the census tract level, without control for individual background (see references in South and Crowder, 1997). Later studies, in contrast, employ a greater range of methods and methodologies, including analyses of subjective preferences and mobility choices. According to this literature, Whites are not a uniform group with predictable preferences. As postulated in the classic tipping-point model (Schelling, 1971), there is a large variation in residential preferences within the group - from those who are relatively tolerant to those who feel threatened by a few Black neighbours (Galster, 1990; Farley et al., 1994; Swaroop and Krysan, 2011).

A related proposition substitutes ethnicity for race. Animosity towards ethnic minorities that have immigrated may not approach the level of hostility towards African Americans, but the theoretical mechanism is still the same: a connection between large or growing minority concentration and native out-mobility, mediated by limited tolerance for 'others'. It is argued, for instance, that US-born Whites, but also Blacks, have limited tolerance for living near Asians and Latinos (Crowder et al., 2011). Some Dutch studies conclude along similar lines, pointing to native attitudes as a key factor behind increasing concentration of ethnic minority residents (Bolt et al., 2008; van Ham and Clark, 2009).

The second version of the flight thesis holds that majority residents tend to leave mixed neighbourhoods because these areas struggle with significant problems - e.g. poverty, lack of safety, pollution and deficient infrastructure (Leven et al., 1976; Taub et al., 1984; Harris, 1999). Race is thus relegated to a secondary concern, with little or no independent impact on out-mobility. It is an argument which finds echoes in immigration research on both sides of the Atlantic. A recent debate over 'white flight' in the United Kingdom is a case in point. One study presents the proxy argument (i.e. the racial proxy hypothesis) in explicit terms: 'those with greater incomes are able to satisfy aspirations for better environment and housing away 
from the low-income areas to which most immigration occurs' (Catney and Simpson, 2010: 2).

The third version perceives a shift in the target of racial prejudice. Ellen (2000a: 47) underlines that many Whites 'tend to hold powerful stereotypes about the social, economic, and physical characteristics of largely minority neighbourhoods'. In contrast to the second version, race does not disappear through control for deprivation and social problems. The cognitive content, however, does not relate to individuals, but to neighbourhoods. It does not matter whether these conceptions are right or wrong; what matters is that Whites are prone to act on race-based stereotypes. A process of neighbourhood change might therefore proceed, although hardly at a rapid pace, given the premise that Whites/natives tolerate or appreciate minority neighbours.

It is this third version that informs our study of native mobility in Oslo. We do not have suitable data to investigate prejudice or preferences. Nor do we direct our attention to local deprivation or quality-of-life characteristics. These latter aspects are incorporated in the research design, but only as potential confounders. We further recognize the similarity between the two propositions through our choice of concepts - 'the original proxy thesis' (Levin, Taub, Harris) and 'the revised proxy thesis' (Ellen).

\section{The role of parents}

If the revised proxy thesis were accurate, we would expect some variation across households in their sensitivity to neighbourhood characteristics. Those who are less invested in the future strength of the neighbourhood are likely to be indifferent to a growing minority population. Conversely, those who engage in the community will be more unstable, given the underlying fear of neighbourhood decline. A consequence that can be drawn is that people with childcare responsibilities behave differently than others: 'Households with children are bound to be more sensitive than others to neighbourhood racial change because of their heightened concern about the environment in which they are raising their children - the safety and cleanliness of the streets; the existence of parks, playgrounds, and other amenities; and most significantly, the quality of local education' (Ellen, 2000a: 55).

The question, of course, is how we should define parenthood. It is clear from research that we cannot simply draw a line between parents and non-parents. Many households start to prepare for family extensions in advance, e.g. by adjusting housing size to the expected family size. An Austrian study is particularly instructive here, since it shows that parents-to-be, i.e. singles and couples expecting their first child, are likely to relocate in the middle of the 
pregnancy (Kulu, 2008). The increased probability is substantial, even compared to parents who expect their second or third child (for additional evidence see: Mulder and Wagner, 1998; Feijten and Mulder, 2002; Clark and Huang, 2003). We therefore predict that:

Native parents and parents-to-be tend to leave mixed neighbourhoods (H1).

Another relevant factor is housing tenure. Conventional knowledge suggests that homeowners are a stable group that develops ties and loyalty to the place they live. This commitment, however, is certainly not natural or inevitable. The existence of powerful stereotypes may turn the logic upside down, since homeowners 'have a financial stake in the future of local property values' (Ellen, 2000a: 100), i.e. homeowners might be 'less willing to live in integrated communities than renters' (ibid: 54). For our purpose, it is not homeownership per se that captures our attention but rather the interaction between parenthood and homeownership. Thus, following Ellen, we propose that:

\section{Homeownership strengthens the effect of parenthood on out-mobility (H2).}

Some other factors play out at the neighbourhood level. Most importantly, majority residents might have faith in the future development of stable neighbourhoods, even if minorities dominate the population structure. What is of concern is the recent change in the minority share, as this might signal decline in neighbourhood quality (Ellen 2000a; 2000b). The prediction we make is that neighbourhood history has a significant impact on out-mobility:

Native parents and parents-to-be respond primarily to change in the ethnic composition. The composition as such has secondary importance (H3).

A final point concerns residential patterning. Neighbourhood stereotypes depend crucially on the specific geography of each region, including factors that bolster the local housing market (Ellen, 2000a). In our case, the most significant feature is a longstanding social division between East and West (Wessel, 2000). The affluent part, West, has far more prestigious institutions than East, and a price level that exceeds East by 25-40 per cent for comparable dwellings (Magnusson Turner and Wessel, 2013). We therefore submit the following hypothesis:

Enhanced outflow of native parents occurs primarily in Oslo East (H4). 
Our four propositions do not amount to a full-scale test of the revised proxy thesis. The thesis posits, for instance, that entry decisions are more important drivers of neighbourhood change than exit decisions, since in-movers lack direct experience with the neighbourhood's problems and qualities. To investigate both flows, however, would take us too far afield from the focus of the current paper. Similarly, while we attend to parental behaviour, we do not examine the entire variety of factors that influences parents' geographies. Our study may be seen as a twist to that field. ${ }^{3}$

\section{Data and methods}

The data in this study derive from a longitudinal database containing information on all residents in the Oslo area, which is defined as the municipality of Oslo plus 12 surrounding municipalities. We have merged a large number of socioeconomic and demographic variables at the individual level, including several neighbourhood indicators. The sample ('natives') consists of individuals who fulfil four criteria: i) they are born in Norway and have two Norwegian-born parents, ii) they were between 25 and 50 years of age on January 1, 2010, iii) they lived in the selected area on the same date, and iv) they lived in Norway on January 1, 2011. Our control group has the same age characteristics, and lived in the same area during 2010. This group ('non-natives') consists of immigrants and descendants from 184 non-rich countries (OECD, 2011). ${ }^{4}$

We define neighbourhoods as census tracts, in line with many other Norwegian studies. Tracts with less than 50 residents were removed from the dataset before any other operations were made. The final sample counts 1,337 tracts, with a total population of 991,227 residents, and with 260,769 in the selected age-span. We believe these areas (average: 740 residents) are sufficiently small to capture clusters of residences that affect mobility decisions and mobility flows. Census tracts in Norway are based on local knowledge, and should be homogeneous with respect to communications, industry and demographic structure.

\section{Dependent variable: out-mobility}

Our key concern is out-mobility from neighbourhoods with large or increasing shares of ethnic minorities. The main part of the study explores movements across tracts during the calendar year 2010. We try to gauge the impact of parenthood and neighbourhood characteristics simultaneously, without any distinction between different types of movement. The values on this variable are 1 for those who relocate in a different tract and 0 otherwise. 
Native responses to ethnic minorities may stem from many sources - skin colour, language, religion, clothing and cultural practices. For this study, we have chosen a rather low threshold of tolerance, namely the tolerance for non-Nordic neighbours. Our rationale is that native parents, like all parents, are preoccupied with their children's learning environments. Such concerns may induce mobility even if the neighbourhood includes a large share of minorities from Continental Europe, given that these groups have to acquire Norwegian as a second language. Nordic people, by contrast, can easily understand each other, and have been wandering across the borders for centuries. ${ }^{5}$

The exact indicators in the analysis are: i) the share of immigrants and descendants from non-Nordic countries in 2010, ii) change in the share of immigrants and descendants from non-Nordic countries during 2005-2010.

The presence of children in the household is the main distinction at the individual level. We include stepparents and foster parents on equal terms with biological parents, and exclude parents who live apart from their children. The age limit for children is 17 years of age. We distinguish between households according to age of the youngest child: i) 0-5 years, and ii) 617 years. Our concepts for the two categories are 'BA-parents' (youngest child 0-5) and 'BBparents' (youngest child 6-17), which correspond to the symbols in the Norwegian classification of households.

As noted, we also include a category for parents-to-be: 'future parents' include individuals who had their first child in 2010 or 2011 . We thus hypothesise and test whether pregnancy and planning for pregnancy induce residential moves, in line with extant theory.

\section{Control variables}

Our most important control variable at the individual level, housing tenure, equals 1 for homeowners and 0 otherwise. The measure is based on tax settlement data for 2009 , due to lack of a proper housing register in Norway. Previous research, and some controls in this study, show that tax settlement data agree well with census measurements. One potential problem, however, stems from the fact that tax settlement data relate to the whole calendar year. This may lead to misclassification if people moved from an owner-occupied to a rental dwelling during 2009. The prevalence of such moves is, fortunately, extremely small (see Aarland and Nordvik, 2009)

Another important control task is to capture neighbourhood deprivation and housing structure, since these characteristics coincide with minority share. Deprivation is measured 
through a composite index with four indicators, all relating to individuals between 25 and 50 years of age: i) the share with primary school as the highest level of completed education, ii) the share with net income in the first quintile, using thresholds at the metropolitan level, iii) the level of unemployment, iv) the share who receive either social assistance or housing allowance benefit. The outcomes on each indicator were transformed to z-scores with means equal to 0 and standard deviations equal to 1 . A subsequent estimation of averages for each census tract produced the aggregate index. We conducted the operation for two years, 2004 and 2009, controlling for current status as well as change. Housing structure is measured by the share of blocks (2010), including both low-rise and high-rise blocks.

Other control variables are: age, age squared (to capture non-linear effects of age), log income (natural log), gender, civil status, highest completed education, reception of unemployment benefits, reception of social allowance/housing assistance, location in the outer city and duration of residence in the census tract. We use binary coding for the majority of these variables, but not for education, income, age and duration of residence. Education is a continuous variable that varies between 0 (no education) and $8(\mathrm{PhD})$. Income is defined as income after tax, which implies that tax is subtracted from gross income (wage, selfemployment income, capital income and transfers). Age and duration of residence are measured in years, with 1990 as the first year of registration for residence. The outer city contains all suburbs in the municipality of Oslo (township 6-15) plus 12 municipalities in the county of Akershus (municipality 213-214, 216-220, 228 and 230-235).

Most of the individual-level variables are part of the standard repertoire in mobility studies. Two of them, however, may need some further explanation. Location in the outer city is included because building density is known to affect both housing preferences and housing market mobility (van Ham and Clark, 2009). Duration of residence is included to account for time-dependent neighbourhood attachment (Nordvik and Magnusson Turner, 2015), further as a control for selection into the current neighbourhood.

\section{Geographical analysis}

Our evaluation of geographic patterns revolves around the division between East and West. West contains seven townships in Oslo, number 4-8 and the larger part of 14 (minus subarea 1405). West also contains two municipalities in Akershus, number 219 and 220. 


\section{Analytical strategy}

We estimate the probability that individuals will move out of their current neighbourhood as a linear function of individual and neighbourhood characteristics. D represents household categories, which are constructed according to the presence or expectation of children. $\mathrm{B}$ is the minority share, $\Delta \mathrm{B}_{\mathrm{t} 1, t 0}$ is change in the minority share, $\mathrm{C}$ is housing tenure at $\mathrm{t}_{1}, \mathrm{X}$ stands for all other controls and $\varepsilon$ is a residual:

$P=\beta^{D} D+\beta^{B} B+\gamma^{B} \Delta B_{t 1, t 0}+\beta^{D B C} D B C+\gamma^{D \Delta B_{t 1, t 0}} D \Delta B_{t 1, t 0} C+\mu X+\varepsilon$

The question regarding levels of ethnic concentration is crudely covered through the first interaction term. To improve the answer, however, we also provide predicted margins for chosen values of B. This analysis is presented through graphical figures instead of regression estimates.

We report robust standard errors to account for clustering of individuals in neighbourhoods. Multicollinearity diagnostics were acceptable for all variables in the analysis. The highest level of variation inflation (VIF) for any key variable (first-order term) is 2.3 ( $\mathrm{z}$-score for deprivation).

\section{Descriptive statistics}

Table 1 provides detailed summary statistics for all variables used in the regression analyses. About $16 \%$ of the sample population moved to a different tract, either inside or outside the Oslo area, during 2010. The household categories are unevenly represented, with the reference category (households without children) as the largest (44.6\%) and future parents as the smallest $(6.3 \%)$. Mean share of non-Nordic residents in the neighbourhood is $25.7 \%$, compared to $42.1 \%$ in the control group. We further note that non-natives have less socioeconomic resources and a larger representation of BA-parents.

\section{(TABLE 1 HERE)}

\section{Out-mobility}

Our analysis of out-mobility during 2010 is presented in Table 2. Model 1 is a baseline with key characteristics at the individual and neighbourhood level, including square terms to account for non-linear effects of minority presence and local deprivation. The results indicate, as expected, that parenthood is a key driver of housing market mobility and stability. Future 
parents have a vastly higher level of mobility than any other groups, whereas the opposite applies to BB-parents. A negative effect for BA-parents might seem surprising given our hypotheses. It is quite comprehensible, however, if we consider the structure and functioning of the Oslo housing market. A large group of young people tend to move from flat to flat, adapting to a volatile supply of rented dwellings. Many individuals in this group are included in the reference category and are bound to reduce the empirical value of Model 1. What we may note is that none of the neighbourhood variables lend support to the revised proxy thesis. The effect of minority presence is moderate for the static variable, but negative for the dynamic variable. We also observe zero or negative effects for non-natives.

Model 2 includes control for age, gender, civil status, educational level, income, unemployment, reception of social/housing assistance, housing tenure, geographical location and share of blocks in the neighbourhood. With this extension, the revised proxy thesis receives more support. The effect for BA-parents is now positive (0.026), in support of hypothesis 1 . Both minority variables change in magnitude, but not in sign, and fail to support hypothesis 3. Hence, our interpretation is that Model 2 resonates with both versions of the proxy thesis. As in Model 1, BB-parents are not a mobile group, but rather the opposite. Several control variables, particularly housing tenure, display results that point in the same direction. Native homeowners have a strong inclination to stay in their present dwelling, independent of demographic and socioeconomic characteristics.

Non-natives display some similar and some dissimilar features. Most importantly, this group is far more affected by socio-economic characteristics at the individual and neighbourhood level. Education, for instance, has a large effect for non-natives but no effect for natives.

\section{(TABLE 2 HERE)}

The results reported above may be seen as an overview, a crude glimpse of native mobility in a city with numerous multi-ethnic districts. To parse out more details, Model 3 includes two sets of interaction terms. The first set contains a combination between household status, housing tenure and minority share, whereas the second set substitutes minority share for change in the same share. Most of these coefficients reach statistical significance and highlight some disparate effects on native mobility. To begin with, all three parental categories are more likely than other residents to leave mixed neighbourhoods. The effect of minority presence is largest for BA-parents, second largest for future parents and smallest for 
BB-parents. Two of the groups, BA-parents and BB-parents, are less stable in the owneroccupied sector, whereas the opposite applies to future parents. We may therefore conclude that hypothesis 1 is strengthened for all three groups, whereas hypothesis 2 is strengthened for existing parents. One plausible reason for the latter outcome is that future parents, partly due to age, have accumulated less capital than BA-parents and BB-parents. ${ }^{6}$

Interestingly, we do not observe similar effects for change in minority share. All these estimates are negative, which implies that natives are likely to move from neighbourhoods with decreasing, stable or slow growth in minority presence. This outcome is clearly surprising, but it becomes more understandable when we scrutinize the involved variables. One would normally expect a high correlation between static and dynamic measures of ethnic composition. In our case, however, the correlation is not very high - just 0.39 . The main reason for the low correlation, and for the mismatch between composition measures in Model 3 , is historical in nature and concerns changes in ethnic geographies. The inner city used to be a significant hub for minorities from Asia and Africa, but this started to change in the 1990s. Many Asian and African families moved to the outer city, without being fully replaced by new immigration (Magnusson Turner and Wessel, 2013). These areas have thus experienced minor increases, or even decline, in the share of non-Nordic residents. The crucial point is that inner-city areas also function as a transit port for natives. Young nest-leavers settle in the inner city and stay there through studies and early labour market careers. A typical turning point occurs when the first child arrives, a second when the first child approaches school age. These events coincide with moves from smaller to larger dwellings, and from inner to outer city. $^{7}$

The pattern among non-natives is dramatically different. Only two of the interaction terms reach statistical significance, both with a marginal impact $(0.001, \mathrm{p}<0.01$ and $<0.05)$. Level of education and deprivation in the neighbourhood, by contrast, are highly important. Non-natives are inclined to leave deprived neighbourhoods, whereas the balance between natives and non-natives plays a trivial role.

\section{(FIGURE 1 HERE)}

Figure 1 illustrates how concentration of ethnic minorities affects out-mobility among future parents (upper graph), BA-parents (middle graph) and BB-parents (lower graph). The solid line in each graph represents predicted margins at 10, 20,30, 40, 50 and 60\% non-Nordic residents in the neighbourhood. The dashed line represents the corresponding margins for 
others estimated after control for individual and neighbourhood characteristics (Model 3 in Table 2). The results show, first, a generally high level of out-mobility among future parents. A large flow out of the inner city, and even across districts in the outer rings, explains much of the difference between future parents and others. We notice at the same time a significant increase in the gap between the two groups, from 6.5 percentage points at $10 \%$ minorities to 18.2 percentage points at $60 \%$ minorities, compared to a slightly decreasing gap among nonnatives.

BA-parents have a similar slope, but a different pattern of interaction along the x-axis. At levels of minority concentration below 25-30\%, BA-parents are more stable than other groups. Above this level, BA-parents become more and more unstable, whereas others retain the same level of stability. Again, the curve for non-native parents is almost flat, with no significant difference between low and high levels of ethnic concentration.

As suggested by Model 3, the third group, BB-parents, is less responsive. Compared to others, BB-parents are less likely to move as long as the minority share is below $50 \%$. From this point upwards, the difference between BB-parents and others ceases to be statistically significant. In this case, we may also glimpse a decreasing gap for non-natives, although both curves show overlapping confidence intervals along the x-axis.

\section{Geographic variation}

Figure 2 illustrates population turnover in Oslo East and Oslo West. We differentiate between census tracts according to minority share (\% non-Nordic residents) and mobility rate (\% outmobility during 2010), with two thresholds for minority share (80 and 120\%) and one threshold (120\%) for out-mobility. The first category ('high share, unstable') includes tracts that exceed the highest threshold on both variables. The second category ('high share, stable/fairly stable') exceeds the $120 \%$ threshold in terms of minority share, but not in terms of mobility. Next, we have two categories with a moderate minority share (between 80 and $120 \%$ ), which is combined with high mobility ('moderate share, unstable') and low/moderate mobility ('moderate share, stable/fairly stable'). A rest-category ('other') contains all tracts with a low minority share (below $80 \%$ ). To avoid excessive details, we only include an aggregate of the three parental categories.

(FIGURE 2 HERE) 


\section{Complementary tests}

We conducted several analyses to ensure that our core results are robust with regard to specification. First, we explored whether some of the household categories contain internal heterogeneity. 'Future parents' is clearly a candidate for such variation, given the extended period of observation. Part of the group moved before pregnancy and these individuals may have responded to other factors than family extension. We tested this prospect by a regression that substitutes the aggregate category (future parents) by distinct categories for birth in 2010 and 2011. The results are presented in Appendix 1 (column 2-3), and resemble the pattern in Model 3 (Appendix 1, column 1). A similar test for BB-parents with the youngest child in two age groups, 6-12 and 13-17, gave similar results: nine out of 12 estimates were identical at the three-digit level (Appendix 1, column 4-5). Slightly more, but not larger differences occurred when we excluded individuals with more than one child as a test of adjustment moves generated by older siblings (Appendix 1, column 6). 
Another source of concern is the measurement of neighbourhood characteristics. We tested several versions of deprivation, using different indicators and measurement techniques. None of the alternative choices altered the main pattern, regardless of whether we reduced or increased the number of indicators. The outcome for a single indicator, unemployment, is a typical illustration of the outcomes (Appendix 1, column 7). We further examined whether native responses depend on the specification of minority status. Intuition suggests that anxieties and concerns are directed towards visible minorities, e.g. Asians and Africans. Again, while some estimates changed, we could not discover any biases (Appendix 1, column $8)$.

Third, even though we control for standard correlates of mobility, one might well imagine other drivers of housing search and relocation. Some initial models included variables for gross wealth, net wealth, size of household and more refined specifications of educational level, location and reception of benefits. As these additions and substitutes had trivial effects on out-mobility, we opted for a more parsimonious set of controls. A more striking divergence appeared when we added pairwise products to Model 3, combining household status and four other variables: age, income, neighbourhood deprivation and location in the outer city. With this extension, change in minority share tended to change from negative to positive (Appendix 1, column 9), a pattern that underpins our point regarding outward dispersal of ethnic minorities.

A fourth set of tests explored the choice of a linear probability model. We experimented with a logit model, using predicted margins instead of ordinary coefficient estimates. The results for the interaction terms documented minor differences between the two alternatives (Appendix 1, column 10).

Finally, we also extended the control group to include all immigrants and descendants. This extension did not change the results at all. The interaction term for future parents and BB-parents of non-native background remained insignificant, whereas the terms for BBparents were reduced from 0.0007 to 0.0006 (renters) and from 0.0006 to 0.0005 (owners) (results are available upon request).

\section{Conclusion}

Our analysis of native stability in mixed neighbourhoods documents the significance of parenthood: native parents and parents-to-be display a heightened sensitivity to concentration of ethnic minorities. The observed effect is strengthened by homeownership for those who have entered parenthood, but not for future parents. We thus corroborate our hypothesis 
regarding levels of out-mobility (H1), and to an extent regarding housing tenure (H2). Hypothesis 3 suggested that change in ethnic composition is a more important push-factor than present ethnic composition. This proposition did not receive support in the main analysis; what we observed was the opposite: native parents are more likely to leave neighbourhoods with stable or decreasing minority presence. A further examination of this paradox suggested that two processes coincide. One process is a geographical dispersal of ethnic minority populations from settlement areas in the inner city to suburbs and smaller sub-centres in the region. The other process is a classic adjustment among natives: young Norwegians tend to initiate their housing career in the inner city. We further documented a geographical pattern that fully supports hypothesis 4. Mixed neighbourhoods that experienced extensive native departure were mainly located in Oslo East. A converse pattern, i.e. overrepresentation in West, obtained for stable neighbourhoods with a moderate share of ethnic minorities.

The connection between minority share and out-mobility is clear enough, but does not provide detailed information about the response curve. We therefore investigated the rate of out-mobility at specific levels of ethnic concentration. What we found was a split pattern, depending on the age of the youngest child. Parents of young children (under 6 years of age) were more stable than others as long as the minority share was below 25-30\%. Above this level, the propensity to leave the neighbourhood increased successively, with significant changes for every $10 \%$ increase in minority share. The more established category of parents, called BB-parents, had a lower level of out-mobility at low to medium levels of ethnic concentration, but this feature vanished when the share of minorities exceeded $50 \%$. Future parents were more mobile than others across the whole range of neighbourhoods, from low to high levels of ethnic concentration. The gap increased, however, at high levels of ethnic concentration.

Unlike these results, non-natives responded primarily to deprivation in the neighbourhood, and not to the balance between natives and non-natives. Non-native BAparents, in particular, had a completely different pattern than native BA-parents.

The study as a whole lends substantial support to the revised proxy thesis. There is an effect of neighbourhood ethnic composition on native mobility, and the size of this effect varies according to demographic characteristics, housing tenure and location. It seems highly plausible that native responses reflect psychological, social and economic 'investments' in the neighbourhood. The concrete mechanism that drives the process might be fear, particularly the tendency to interpret high and increasing levels of ethnic concentration as a signal of decreasing neighbourhood quality. A counter-argument would be that responses in Oslo are 
weak compared to the US context. One might also object that some differences in our study are quite small. The outcomes for parent renters and parent owners are a case in point - the disparity between the two groups is not as large as Ellen (2000a) seems to suggest. But again, the very fact that homeowners with children are more unstable than renters with children runs directly counter to the prediction that homeownership enhances stability (Clark, 2012).

As always in this type of study, we cannot fully rule out that the results reflect some unmeasured characteristics at the individual or neighbourhood level. The many tests we have conducted, and the fact that we included a large number of control variables, suggest that parenthood really matters. There is one factor, however, that we fail to capture fully: we did not have extensive information on housing conditions. Our variables for housing tenure and housing structure (share of blocks in the tract) proved to be significant predictors of stability/instability. It would be interesting, therefore, to assess whether housing space, housing type and housing values affect some groups more than others, e.g. whether part of the parenthood effect is a proxy for inadequate or inappropriate housing. The fact that many parents moved from apartments to small houses suggests a role for housing diversity policies. Mixed developments have worked previously in Oslo (Wessel, 2000), but current initiatives appear to head in a different direction. The new master plan for the municipality of Oslo identifies a huge potential for dense development in the Outer East, adding up to 61,000 units, or $54 \%$ of the current housing stock, within 15 years (Oslo municipality, 2015). There is a real danger that these policies might drive even more natives towards homogeneous areas, given that Eastern suburbs have large concentrations of ethnic minorities.

Finally, looking to the future, we see three promising directions for research. The first is to look at changes in the mobility behaviour of native parents. Some of the suburban areas that developed into 'mixed neighbourhoods' experienced large-scale out-migration decades ago, in the early phase of minority settlement. Current inflows and outflows may therefore represent a continuation of processes that were triggered by other factors than ethnic concentration. ${ }^{8}$ The second path is to explore whether single ethnic minorities copy the native pattern. It would not be surprising if groups that experience success on the labour market have started to mimic Norwegians, either because they fear neighbourhood decline or because they adopt the Norwegian housing ideal. The third direction is to examine adjustments to limitations and opportunities in different types of landscape. Some of these adjustments may be less rational, since there are no indications that school segregation affects school results (Fekjær and Birkelund, 2007), and since natives in the chosen age-span display tolerant attitudes towards ethnic minorities (Blom, 2014). Although our analysis provided 
circumstantial evidence for neighbourhood stereotyping as a trigger of relocation, we could not identify the particular mechanism for this when working with register data. One alternative to our explanation is that native parents respond to communication problems, low organizational activity or lack of social cohesion. Such a pattern would be more attuned to the original proxy thesis, with its strong emphasis on social class. It is hard to see, however, why parent owners should experience more problems than parent renters. We therefore perceive Ellen's thesis, i.e. fear of neighbourhood decline, as the primary candidate for explanation.

\section{References}

Aarland K and Nordvik V (2009) On the Path to Homeownership: Money, Family Composition and Low-income Households. Housing Studies 24(1): 81-101.

Aldén L, Hammarstedt M and Neuman E (2015) Ethnic Segregation, Tipping Behaviour, and Native Residential Mobility. International Migration Review 49(1): 35-69.

Andersson R and Bråmå Å (2004) Selective migration in Swedish distressed neighbourhoods: Can area-based urban policies counteract segregation processes. Housing Studies 19(4): 517-539.

Bailey N and Livingston M (2008) Selective migration and neighbourhood deprivation: Evidence from 2001 census migration data for England and Scotland. Urban Studies 45(4): 943-961.

Blom S (2014) Holdninger til innvandrere og innvandring 2014 [Attitudes to immigrants and immigration 2014]. Oslo: Statistics Norway, Report 39/2014.

Bolt G, van Kempen R and van Ham M (2008) Minority Ethnic Groups in the Dutch Housing Market: Spatial Segregation, Relocation Dynamics and Housing Policy. Urban Studies 45(7): 1359-1384.

Boterman, WR (2012) Residential mobility of urban middle classes in the field of parenthood. Environment and Planning A 44(10): 2397-2412.

Catney E and Simpson L (2010) Settlement area migration in England and Wales: assessing evidence for a social gradient. Transactions of the Institute of British Geographers 35(4): $571-584$.

Clark WAV (2012) Residential Mobility and the Housing Market. In: Clapham DF, Clark 
WAV and Gibb K (eds) The Sage Handbook of Housing Studies. Los Angeles, London, New Dehli, Singapore, Washington DC: Sage, pp. 66-83.

Clark WAV and Huang Y (2003) The Life Course and Residential Mobility in British Housing Markets. Environment and Planning A 35(2): 323-339.

Crowder K, Hall M and Tolnay SE (2011) Neighborhood Immigration and Out-Migration. American Sociological Review 76(1): 25-47.

Ellen I Gould (2000a) Sharing Americas Neighborhoods. The Prospects for Stable Racial Integration. Cambridge, MA and London, England: Harvard University Press.

Ellen I Gould (2000b) Race-based Neighbourhood Projection: A Proposed Framework for Understanding New Data on Racial Integration. Urban Studies 36(9): 1513-1533.

Farley R, Steeh C, Krysan M, Jackson T et al. (1994) Stereotypes and Segregation: Neighborhoods in the Detroit Area. American Journal of Sociology 100(3): 750-780.

Feijten P and Mulder CH (2002) The Timing of Household Events and Housing Events in the Netherlands: A Longitudinal Perspective. Housing Studies 17(5): 773-792.

Feijten P and van Ham M (2009) Neighbourhood change ... Reason to Leave? Urban Studies 46(10): 2103-2122.

Fekjær SN and Birkelund G (2007) Does the Ethnic Composition of Upper Secondary School Influence Educational Achievements and Attainment? A Multilevel Analysis of the Norwegian Case. European Sociological Review 23(3): 309-323.

Galster G (1990) Neighborhood Racial Change, Segregationist Sentiments, and Affirmative Marketing Policies. Journal of Urban Economics 27(3): 344-361.

Harris DR (1999) 'Property Values Drop When Blacks Move in, Because ...' Racial and Socioeconomic Determinants of Neighborhood Desirability. American Sociological Review 64(3): 461-479.

Hoyt H (1939) The Structure and Growth of Residential Areas in American Cities. Washington DC: Federal Housing Administration.

Johnston R, Poulsen M and Forrest J (2015) Increasing Diversity Within Increasing Diversity: the Changing Ethnic Composition of London's Neighbourhoods. Population, Space and Place 21(1): 38-53.

Kulu H (2008) Fertility and spatial mobility in the life course: evidence from Austria. 
Environment and Planning A 40(3): 632-652.

Leven CL, Little JT, Nourse HO et al. (1976) Neighborhood Change: Lessons in the Dynamics of Urban Decay. New York: Praeger.

Magnusson Turner L and Wessel T (2013) Upwards, outwards, westwards: relocation of ethnic minority groups in the Oslo region. Geografiska Annaler Series B Human Geography 95(1): 1-16.

Massey DS and Denton NA (1993) American Apartheid. Segregation and the Making of the Underclass. Cambridge MA: Harvard University Press.

Mulder CH and Wagner M (1998) First-time Home-ownership in the Family Life Course: A West German-Dutch Comparison. Urban Studies 35(4): 687-713.

Nordvik V and Magnusson Turner L (2015) Survival and Exits in Neighbourhoods: A Long-Term Analysis. Housing Studies 30(2): 228-251.

OECD (2011) Country classification 2011. Available at: https://www.oecd.org/tad/xcred/48405330.pdf

Oslo municipality (2015) Oslo mot 2030 - smart, trygg og grønn [Oslo towards 2030 smart, safe and green]. Available at: https://www.kommuneplan.oslo.kommune.no.

Schelling T (1971) Dynamic Models of Segregation. Journal of Mathematical Sociology 1(1): 143-86.

South S and Crowder K (1997) Escaping Distressed Neighborhoods: Individual, Community, and Metropolitan Influences. American Journal of Sociology 102(4): 10401084.

Swaroop S and Krysan M (2011) The Determinants of Neighborhood Satisfaction: Racial Proxy Revisited. Demography 48(3): 1203-1229.

Taub R, Garth Taylor D and Dunham J (1984) Paths of Neighborhood Change. Chicago: Chicago University Press.

Van Ham M and Clark WAV (2009) Neighbourhood mobility in context: household moves and changing neighbourhoods in the Netherlands. Environment and Planning A 41(6): 1442-1459.

Wessel T (2000) Social Polarisation and Socioeconomic Segregation in a Welfare State: the 
Case of Oslo. Urban Studies 37(11): 1947-1967.

\section{Notes}

${ }^{1}$ The share of non-Nordic residents in the township that Holmlia belongs to, Søndre Nordstrand, has increased from $39.7 \%$ in 2006 to $51.9 \%$ in 2016.

${ }^{2}$ The search produced 215 hits, using English ('white flight') and Norwegian ('hvit flukt'). Changes in the Oslo region were discussed in $84 \%$ of the articles.

${ }^{3}$ Much of the recent scholarship in Europe discusses residential mobility among middle-class families. Our study, by contrast, has more important implications for working-class families and working-class areas.

${ }^{4}$ OECD's classification includes all countries in Africa and Latin America, and all but three countries (Israel, South Korea and Japan) in Asia. Several countries, e.g. Chile, has changed their status since 2010.

${ }^{5}$ Most Finns have a different language, but the Finnish group in the selected area is very small $(0.9 \%$ of the immigrant population).

${ }^{6}$ Net wealth for future parents is NOK -450,000, compared to NOK -233,000 for BA-parents and NOK 261,000 for BB-parents.

${ }^{7}$ The housing structure in gentrified areas includes many small dwellings, which prevents large-scale family gentrification. It is possible, though, that distinct subgroups of the middle class, e.g. those with high economic capital, are 'selected' to the outer city (see Boterman, 2012).

${ }^{8}$ This perspective implies that changes in the residential landscape may be seen as replacement, and not as displacement. 
Table 1. Descriptive statistics

\begin{tabular}{lrrrr}
\hline & \multicolumn{3}{c}{ Natives } & \multicolumn{2}{c}{ Non-natives } \\
\cline { 2 - 5 } & Mean & SD & Mean & SD \\
\hline Dependent variables & & & & \\
Out-mobility & 0.159 & 0.366 & 0.185 & 0.389 \\
Independent variables: individual level & & & & \\
Future parents & 0.063 & 0.243 & 0.045 & 0.206 \\
BA-parents & 0.236 & 0.424 & 0.355 & 0.477 \\
BB-parents & 0.255 & 0.436 & 0.223 & 0.416 \\
No children & 0.446 & 0.497 & 0.384 & 0.486 \\
Age & 37.7 & 7.2 & 36.7 & 7.2 \\
Female & 0.500 & 0.500 & 0.514 & 0.500 \\
Unmarried & 0.555 & 0.495 & 0.225 & 0.417 \\
Married or registered partner & 0.358 & 0.479 & 0.611 & 0.488 \\
Divorced, separated, widow(er) & 0.087 & 0.281 & 0.164 & 0.371 \\
Education & 5.030 & 1.668 & 3.791 & 2.015 \\
Log income & 12.575 & 1.363 & 11.397 & 2.931 \\
Unemployment benefit & 0.044 & 0.205 & 0.086 & 0.280 \\
Social assistance/housing allowance & 0.039 & 0.193 & 0.147 & 0.355 \\
Homeownership & 0.757 & 0.429 & 0.643 & 0.479 \\
Duration of residence & 5.9 & 5.8 & 3.7 & 4.2 \\
Location in outer city & & & & \\
Independent variables: neighbourhood level & 0.732 & 0.443 & 0.748 & 0.434 \\
Minority share & & & & \\
Change in minority share, 2005-2010 & 0.257 & 0.122 & 0.421 & 0.196 \\
\hline & 0.066 & 0.064 & 0.095 & 0.085 \\
\hline
\end{tabular}


Deprivation status: z-score, 2009

$-0.023$

0.582

0.379

0.805

Change in deprivation: z-score, 2004-2009

$-0.603$

1.691

$-1.352 \quad 1.949$

Share of blocks

0.460

$0.418 \quad 0.633$

0.379 
Table 2. Linear probability models of out-mobility. Robust standard errors

\begin{tabular}{|c|c|c|c|c|c|c|}
\hline & \multicolumn{2}{|c|}{ Model 1} & \multicolumn{2}{|c|}{ Model 2} & \multicolumn{2}{|c|}{ Model 3} \\
\hline & Natives & Non-natives & Natives & Non-natives & Natives & Non-natives \\
\hline \multicolumn{7}{|l|}{ Key individual characteristics } \\
\hline Future parents & $0.114 * * *$ & $0.047 * * *$ & $0.106 * * *$ & $0.037 * * *$ & $0.079^{* * *}$ & $0.052^{* * *}$ \\
\hline BA-parents & $-0.036^{* * *}$ & $-0.091 * * *$ & $0.024 * * *$ & $-0.049 * * *$ & $-0.036^{* *}$ & $-0.061 * * *$ \\
\hline BB-parents & $-0.120^{* * *}$ & $-0.137 * * *$ & $-0.008 * * *$ & $-0.048 * * *$ & $-0.023 * * *$ & $-0.068 * * *$ \\
\hline \multicolumn{7}{|l|}{ Key neighbourhood characteristics } \\
\hline Minority share & $0.005 * * *$ & -0.000 & $0.001 * * *$ & -0.000 & 0.000 & -0.005 \\
\hline Minority share squared & $-0.001 * * *$ & $-0.000 * *$ & $0.000^{* *}$ & 0.000 & -0.000 & 0.000 \\
\hline Change in minority share & $-0.003 * * *$ & $-0.001 * * *$ & -0.000 & 0.000 & 0.000 & 0.001 \\
\hline \multicolumn{7}{|l|}{ Control variables } \\
\hline Deprivation status: $\mathrm{z}$-score & & & $0.006 * * *$ & $0.012 * *$ & $0.006 * *$ & $0.013 * * *$ \\
\hline Deprivation status: z-score squared & & & 0.001 & -0.000 & 0.001 & -0.000 \\
\hline Change in deprivation: $\mathrm{z}$-score & & & $0.002 * * *$ & $0.003 * * *$ & $0.002 * *$ & $0.003 * *$ \\
\hline Age & & & $-0.032 * * *$ & $-0.011^{* *}$ & $-0.030^{* * *}$ & $-0.011^{* * *}$ \\
\hline Age squared & & & $0.000^{* * *}$ & $0.000^{* *}$ & $0.000^{* * *}$ & $0.001 * *$ \\
\hline Gender (female) & & & -0.002 & $-0.030 * * *$ & -0.002 & $-0.031 * * *$ \\
\hline Married, registered partner & & & $-0.008 * * *$ & $-0.020^{* * * *}$ & $-0.009 * * *$ & $-0.020^{* * *}$ \\
\hline Divorced, separated, widow(er) & & & $0.046^{* * *}$ & $0.024 * * *$ & $0.046^{* * *}$ & $0.024 * * *$ \\
\hline Education & & & -0.001 & $0.007 * * *$ & -0.000 & $0.007 * * *$ \\
\hline Log income & & & $0.002 * *$ & 0.000 & $0.003^{* * *}$ & 0.000 \\
\hline Unemployment benefit & & & $0.023 * * *$ & $0.033 * * *$ & $0.022^{* * *}$ & $0.033^{* * *}$ \\
\hline Social assistance/housing allowance & & & $-0.011 * *$ & 0.003 & $-0.010^{* *}$ & 0.002 \\
\hline Homeownership & & & $-0.134 * * *$ & $-0.058 * * *$ & $-0.122 * * *$ & $-0.055^{* * *}$ \\
\hline Duration of residence & & & $-0.001 * * *$ & $-0.006 * * *$ & $-0.001 * * *$ & $-0.006 * * *$ \\
\hline Location in outer city & & & $-0.037 * * *$ & $-0.067 * * *$ & $-0.038^{* * *}$ & $-0.069 * * *$ \\
\hline Share of blocks & & & $0.000 * * *$ & -0.000 & $0.000^{* * *}$ & -0.000 \\
\hline \multicolumn{7}{|l|}{ Interaction terms } \\
\hline Future parents/tenure/min. share: owners & & & & & $0.002^{* * *}$ & -0.001 \\
\hline Future parents/tenure/min. share: renters & & & & & $0.003^{* * *}$ & -0.001 \\
\hline BA-parents/tenure/min. share: owners & & & & & $0.004^{* * *}$ & -0.001 \\
\hline BA-parents/tenure/min. share: renters & & & & & $0.003^{* * *}$ & 0.000 \\
\hline
\end{tabular}


BB-parents/tenure/min. share: owners

BB-parents/tenure/min. share: renters

Future parents/tenure/change share: owners

Future parents/tenure/change share: renters

BA-parents/tenure/change share: owners

BA-parents/tenure/change share: renters

BB-parents/tenure/change share: owners

$\mathrm{BB}$-parents/tenure/change share: renters

Constant

$R^{2}$

$R^{2}$
$N$

0.038

$0.119 * * *$

$0.256^{* * *}$

0.027
$0.02 *$

67,695

0.095

0.095

$0.632 * * *$

$0.001 * * *$

$0.001 * *$

$-0.001 * * \quad 0.000$

$-0.004 * * * \quad 0.001$

$-0.002-0.002$

Notes: $* p<0.05, * * p<0.01, * * * p<0.001$.

$-0.007 * * * \quad-0.001$

$-0.002 * * * \quad 0.001 *$

$-0.002 * * * \quad-0.007$

$-0.000 \quad-0.008$

Min. share $=$ minority share. Change share $=$ change in minority share . 

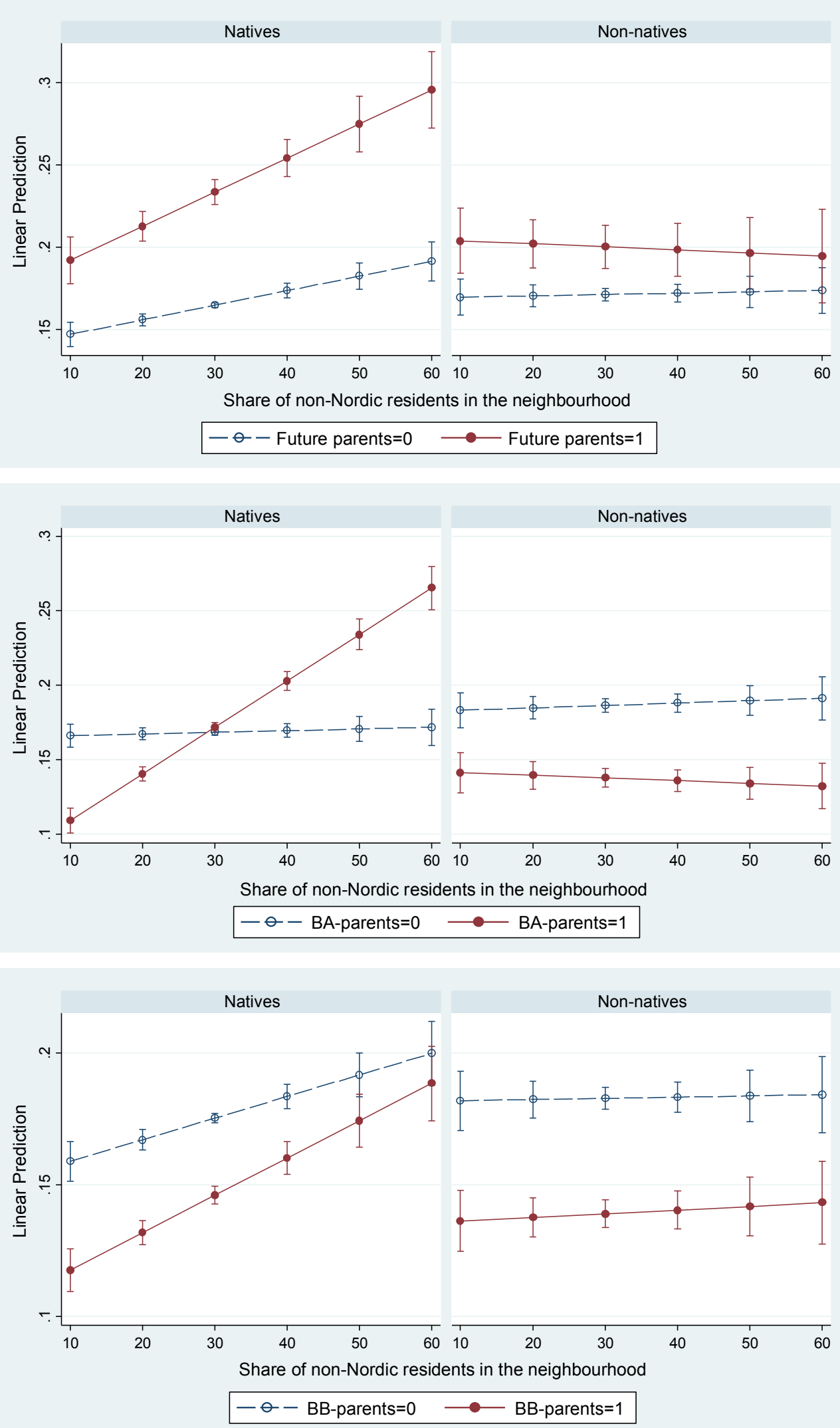

Figure 1. Predicted margins of out-mobility at 10, 20, 30, 40, 50 and $60 \%$ non-Nordic residents in the tract, with $95 \%$ confidence intervals, based on Model 3, Table 2. 


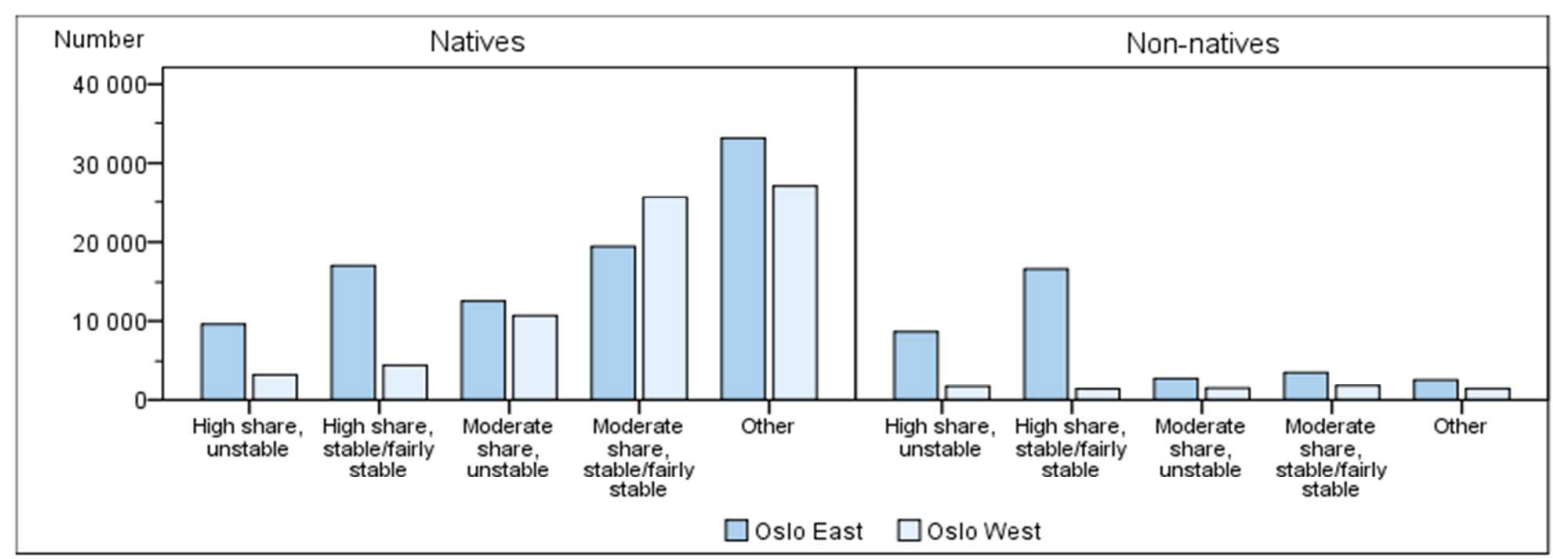

Figure 2. Distribution of parents across types of neighbourhood and location in Oslo East/West 
Appendix 1: Robustness to alternative specifications: key interaction terms

\begin{tabular}{|c|c|c|c|c|c|c|c|c|c|c|}
\hline & (1) & (2) & (3) & (4) & (5) & (6) & (7) & (8) & (9) & $(10)$ \\
\hline Interaction terms & $\begin{array}{l}\text { Table 2, } \\
\text { Model } 3\end{array}$ & $\begin{array}{c}\text { First birth } \\
2010\end{array}$ & $\begin{array}{c}\text { First birth } \\
2011\end{array}$ & $\begin{array}{c}\text { BB-parents } \\
6-12\end{array}$ & $\begin{array}{c}\text { BB-parents } \\
13-17\end{array}$ & $\begin{array}{l}\text { s Restricted } \\
\text { population }\end{array}$ & $\begin{array}{l}\text { Minorities: } \\
\text { Asia/Africa }\end{array}$ & $\begin{array}{c}\text { Unemploy- } \\
\text { ment }\end{array}$ & $\begin{array}{l}\text { - Additional } \\
\text { interaction }\end{array}$ & $\begin{array}{l}\text { Logit } \\
\text { AME }\end{array}$ \\
\hline Future parents \# tenure \# minority share: owners & $0.002 * * *$ & $0.003^{* * *}$ & $0.002 * * *$ & $0.002 * * *$ & $0.002 * * *$ & $* 0.002 * * *$ & $0.003 * * *$ & $0.002 * * *$ & $0.001 *$ & $0.003 * * *$ \\
\hline Future parents \# tenure \# minority share: renters & $0.003 * * *$ & $0.004 * * *$ & 0.002 & $0.003 * * *$ & $0.003 * * *$ & $* 0.003 * * *$ & $0.003 * * *$ & $0.003 * * *$ & 0.001 & $0.004 * * *$ \\
\hline BA-parents \# tenure \# minority share: owners & $0.004 * * *$ & $0.004 * * *$ & $0.004 * * *$ & $0.004 * * *$ & $0.004 * * *$ & $* 0.004 * * *$ & $0.004 * * *$ & $0.004 * * *$ & $0.003 * * *$ & $0.003 * * *$ \\
\hline BA-parents \# tenure \# minority share: renters & $0.003 * * *$ & $0.003 * * *$ & $0.003 * * *$ & $0.003 * * *$ & $0.003 * * *$ & 0.001 & $0.002 * * *$ & $0.003 * * *$ & $0.002 * *$ & $0.003 * * *$ \\
\hline BB-parents \# tenure \# minority share: owners & $0.001 * * *$ & $0.001 * * *$ & $0.001 * * *$ & $0.002 * * *$ & $0.001 * * *$ & $* 0.001 * * *$ & $0.001 * * *$ & $0.001 * * *$ & $0.001 * * *$ & $0.002 * * *$ \\
\hline BB-parents \# tenure \# minority share: renters & $-0.001 * *$ & $-0.001 * *$ & $-0.001 * *$ & -0.000 & $-0.002 * * *$ & -0.001 & $-0.001 * *$ & $-0.001 * *$ & $-0.001 *$ & $0.001 * * *$ \\
\hline Future parents \# tenure \# change in minority share: & $-0.004 * * *$ & $-0.006 * * *$ & $-0.002 *$ & $-0.003 * * *$ & $-0.003 * * *$ & $*-0.004 * * *$ & $-0.003 * *$ & $-0.003 * * *$ & -0.001 & $-0.003 * * *$ \\
\hline Future parents \# tenure \# change in minority share: & -0.002 & $-0.004 *$ & -0.000 & -0.002 & -0.002 & -0.002 & -0.002 & $-0.002 * * *$ & 0.001 & -0.000 \\
\hline BA-parents \# tenure \# change in minority share: owners & $-0.007 * * *$ & $-0.007 * * *$ & $-0.007 * * *$ & $-0.007 * * *$ & $-0.007 * * *$ & * $-0.006 * * *$ & $-0.007 * * *$ & $-0.007 * * *$ & $-0.003 * * *$ & $-0.005 * * *$ \\
\hline BA-parents \# tenure \# change in minority share: renters & $-0.002 * *$ & $-0.002 * * *$ & $-0.002 * * *$ & $-0.002 * * *$ & $-0.002 * * *$ & 0.001 & 0.002 & $-0.002 * *$ & 0.001 & -0.001 \\
\hline BB-parents \# tenure \# change in minority share: owners & $-0.002 * * *$ & $-0.002 * * *$ & $-0.002 * * *$ & $-0.003 * * *$ & $-0.002 * * *$ & $*-0.002 * * *$ & $-0.002 * *$ & $-0.002 * * *$ & $-0.001 * * *$ & $-0.002 * * *$ \\
\hline BB-parents \# tenure \# change in minority share: renters & -0.000 & -0.000 & -0.000 & -0.001 & 0.002 & -0.001 & 0.002 & -0.000 & 0.000 & 0.001 \\
\hline
\end{tabular}

Notes: $* p<0.05, * * p<0.01, * * * p<0.001$. 